\title{
KENDALI PENERANGAN RUMAH JARAK JAUH MENGGUNAKAN SHORT MESSAGE SERVICE (SMS)
}

\author{
Aziz Ahmadi ${ }^{*}$
}

\begin{abstract}
In comunicating handphone/ponsel with microcontroller to be able to used as a instrument of long distance controller it is needed an interface that can synchronize both device so that it can mutually exchange data. Interface system in this research uses communication stripe port of data found on under part of handphone to be able to communicate with microcontroller serially.This tool is made by using controller of microcontroller as principal module, that will read SMS that step into handphone as a command in controlling to realize in mikrokontroler output, also command handphone to send sms output status reply to sender's handphone. In this thesis it can be used most of all handphone types that has equiped $A T$ command facilities with data cable spesification that related to instrument serially, while for controlling it can be used any handphone with SMS facilities. But it can only use XL and IM3 number for controlling. This tool has been tested by using 8 lamps with 220 volt, in which every lamp represents one output stripe as controlling on/off. the testing form is by trying to turn on or turn off all eight lamps, from the testing result it can be concluded that handphone can be accessed well by microcontroller pass through its serial data port so that can be used as a instrument of long distance controller.
\end{abstract}

Key Words: Control, Lightness, Short Message Service (SMS)

\section{PENDAHULUAN}

Seiring dengan berkembangnya teknologi nirkabel (wireless), salah satunya adalah teknologi GSM (Global System for Mobile Communications) yang semakin murah dan dengan kapasitas jangkauan yang semakin luas, menyebabkan pemakaian telepon selular tidak hanya berada pada salah satu golongan masyarakat tertentu saja, namun pemakai telepon selular sudah menjangkau semua lapisan masyarakat. SMS (Short Message Service) adalah salah satu fasilitas yang terdapat pada telepon selular yang hampir setiap orang mengenalnya. Selain memiliki biaya operasional yang cukup murah, fasilitas ini juga merupakan media komunikasi dan sarana informasi antar individu yang cukup memiliki sifat waktu nyata (realtime), sehingga tidak mengherankan apabila SMS masih tetap menjadi pilihan bagi setiap orang sebagai sarana komunikasi.

Kondisi pengontrolan instalasi listrik pada kehidupan masyarakat saat ini masih tergolong konvensional yaitu relatif hanya menggunakan prinsip pengontrolan jarak dekat (manual) atau bisa disebut prinsip pengontrolan yang belum mampu dilakukan pada jarak jauh, karena itu perlu dibuat sebuah alat pengendali penerangan rumah yang prinsip pengontrolannya bisa dilakukan dari jarak jauh dengan harapan dapat memudahkan pemilik rumah yang sekarang sebagian besar sibuk dengan kegiatan di luar rumah sehingga mempunyai kendala waktu dan jarak dalam hal mengontrol atau mengendalikan penerangan di rumah tinggalnya.

Berdasarkan hal di atas maka tercipta ide pembuatan sebuah alat yang dapat mengendalikan lampu dari jarak jauh yang secara praktis dapat digunakan untuk menyalakan atau mematikan lampu rumah. Alat ini merupakan pengendali penerangan lampu rumah dari jarak jauh yang menggunakan gabungan antara SMS dan mikrokontroler, sehingga lampu bisa dihidupkan dan dimatikan tergantung perintah yang ada dari SMS. Sensor cahaya sendiri bermanfaat untuk mengetahui apakah terdapat lampu yang mati akibat putus atau tidak.

*Pemerhati fisika 


\section{KAJIAN TEORI}

Layanan berbasis komunikasi data terus berkembang luas hampir kesemua kalangan masyarakat. Dengan dikembangkannya SMS, pengiriman pesan menjadi lebih mudah. SMS dapat dipergunakan untuk mengirim pesan singkat sebanyak 160 karakter per satu frame atau satuan paket. (Nuraini Silalahi, 2002: 26)

\section{SMS (Short Message Service)}

SMS merupakan salah satu layanan pesan teks yang dikembangkan dan distandarisasi oleh suatu badan yang bernama ETSI (European Telecomunication Standards Institute) sebagai bagian dari pengembangan GSM Phase 2, yang terdapat pada dokumentasi GSM 03.40 dan GSM 03.38. Fitur SMS ini memungkinkan perangkat Stasiun Seluler Digital (Digital Cellular Terminal) seperti ponsel untuk dapat mengirim dan menerima pesanpesan teks. (ETSI, 1996)

SMS dapat dikirimkan ke perangkat Stasiun Seluler Digital lainnya hanya dalam beberapa detik selama berada pada jangkauan pelayanan GSM. Lebih dari sekedar pengiriman pesan biasa, layanan SMS memberikan garansi SMS akan sampai pada tujuan meskipun perangkat yang dituju sedang tidak aktif yang dapat disebabkan karena sedang dalam kondisi mati atau berada di luar jangkauan layanan GSM. Jaringan SMS akan menyimpan sementara pesan yang belum terkirim, dan akan segera mengirimkan ke perangkat yang dituju setelah adanya tanda kehadiran dari perangkat di jaringan tersebut.

Dalam proses pengiriman atau penerimaan pesan pendek (SMS), data yang dikirim maupun diterima oleh stasiun bergerak menggunakan salah satu dari 2 mode yang ada, yaitu: mode teks dan mode PDU.

Semua informasi yang terdapat dalam PDU, dituliskan dalam bentuk pasanganpasangan bilangan heksadesimal yang disebut dengan pasangan oktet. Jenis PDU SMS yang akan digunakan adalah SMS Penerimaan (SMS Deliver) dan SMS Pengiriman (SMS Submit). (Le Bodic, 2002).

\section{Mikrokontroler AT89S8252}

Pada dasarnya mikrokontroler terdiri dari mikroprosesor, timer dan counter, perangkat I/O dan internal memori. Mikrokontroler mempunyai fungsi yang sama dengan mikroprosesor, yaitu untuk mengontrol kerja suatu sistem. Di dalam mikrokontroler terdapat CPU, ALU, PC, SP, dan register lain yang terdapat pada mikroprosesor, tetapi dengan penambahan perangkat-perangkat lain seperti ROM, RAM, PIO, SIO, Counter, dan rangkaian Clock. (ATMEL, 2002)

\section{Arsitektur Mikrokontroler AT89S8252}

Mikrokontroler Atmel AT89S8252 memiliki kelengkapan sebagai berikut:

a) Kompatibel dengan mikrokontroler MCS-51

b) 8 Kbit downloadable flast memori

c) 2 Kbit EEPROM

d) Level program memori lock

e) 256 bit RAM internal

f) $32 \mathrm{I} / \mathrm{O}$ yang dapat dipakai semua

g) 3 buah timer/counter 16 bit

h) Programmable watchog timer

i) Dual data pointer

j) Frekuensi kerja 0 sampai $24 \mathrm{MHz}$

k) Tegangan operasi 2,7 volt sampai 6 volt (Ibnu Malik, 2003: 33) 


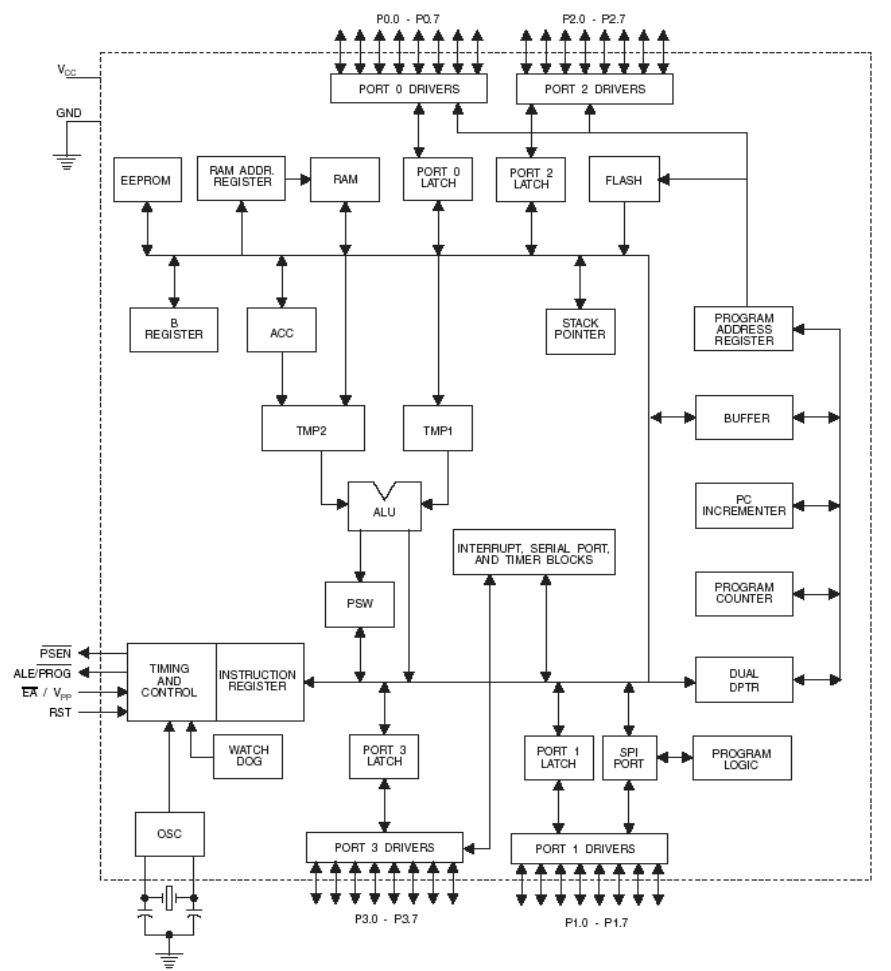

Gambar 1. Blok Diagram AT89S8252

\section{Rangkaian Osilator}

Jantung dari mikrokontroler AT89S8252 terletak pada rangkaian yang membangkitkan pulsa clock. Pin XTAL1 dan XTAL2 disediakan untuk disambungkan dengan jaringan resonan untuk membentuk sebuah osilator. AT89S8252 dirancang untuk running pada frekuensi $3 \mathrm{MHz}$ sampai $24 \mathrm{MHz}$.

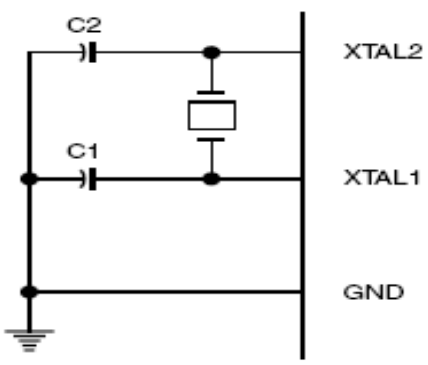

Gamabar 2. Rangkaian Oscillator AT89S8252

\section{Memori Data Internal}

Pada mikrokontroler 89S8252 terdapat internal memori data. Internal memori data dialamati dengan lebar 1 byte. Lower $256(00 \mathrm{H}-7 \mathrm{FH})$ terdapat pada semua anggota keluarga MCS-51. Pada lower 256 lokasi memori terbagi atas 3 bagian yaitu:

1) Register Bank 0-3

2) Bit Addressable

3) Scratch Pad Area

\section{Memori Data Eksternal}

Untuk megakses memori program eksternal, pin EA dihubungkan ke ground. 16 jalur input/output (pada port 0 dan port 2) difungsikan sebagai bus alamat port 0 mengeluarkan alamat rendah (A0-A7) dari pencacah program (program counter). Pada saat port 0 mengeluarkan alamat rendah, maka sinyal ALE (Address Lacth Enable) akan menahan alamat pada pengunci port 2 yang merupakan alamat tinggi (A8-A15) yang bersama-sama 
alamat rendah (A0-A7) membentuk alamat 16 bit. Sinyal PSEN digunakan untuk membaca memori program eksternal.

Mikrokontroler 89S8252 memiliki data berupa RAM internal sebesar 256 byte. Dari jumlah tersebut, 32 byte terendah dikelompokkan menjadi 4 bank. Tiap-tiap bank terdiri dari 8 register. Pemilihan bank dilakukan melalui register Program Status Word (PSW). 16 byte berikutnya membentuk satu blok memori yang dapat dialamati perbit. Memori data ini dapat diakses baik langsung atau tidak langsung.

\section{AT Commands}

Perintah AT (Hayes AT Command) digunakan untuk berkomunikasi dengan terminal (modem) melalui gerbang serial pada komputer. Dengan penggunaan perintah AT, dapat diketahui atau dibaca kondisi dari terminal, seperti mengetahui kondisi sinyal, kondisi baterai, mengirim pesan, membaca pesan, menambah item pada daftar telepon, dan sebagainya.

Tabel 1. Perintah AT (Hayes AT Command)

\begin{tabular}{|c|c|}
\hline AT Command & Fungsi \\
\hline AT+CMGS & Mengirim pesan \\
\hline AT+CMGR & Membaca pesan \\
\hline AT+CMGF & Format pesan \\
\hline AT+CMGD & Menghapus pesan \\
\hline AT+CNMI & Prosedur indikasi pesan baru \\
\hline AT+CPMS & Pemilihan target memori \\
\hline AT+CSMS & Pemilihan layanan pesan \\
\hline
\end{tabular}

\section{Nomor Pusat Pesan}

Pengiriman dan penerimaan pesan singkat menggunakan dua mode yaitu mode teks dan mode Protocol Data Unit (PDU). PDU adalah format pesan dalam hexadecimal octet dan semidecimal. Kelebihan menggunakan mode PDU adalah dapat melakukan encoding sendiri yang tentunya harus pula didukung oleh perangkat keras dan operator GSM.

Tabel 2. Nomor Pusat Pesan

\begin{tabular}{|l|l|l|}
\hline \multicolumn{1}{|c|}{ Operator } & \multicolumn{1}{|c|}{$\begin{array}{c}\text { Nomor Pusat } \\
\text { Pesan Singkat }\end{array}$} & \multicolumn{1}{c|}{ Format dalam PDU } \\
\hline Mentari [Indosat] & +62816124 & 059126181642 \\
\hline IM3 [Indosat] & +62855000000 & $05912658050000 \mathrm{~F} 0$ \\
\hline XL [Excelcomindo] & +62818445009 & $07912618485400 \mathrm{~F} 9$ \\
\hline Simpati [Telkomsel] & +6281100000 & 06912618010000 \\
\hline As [Telkomsel] & +6281100000 & 06912618010000 \\
\hline Fleksi [Telkomsel] & +62210000 & 069126120000 \\
\hline Three [Hutchinson] & +6289644000001 & $0791268946040000 \mathrm{~F} 1$ \\
\hline
\end{tabular}

\section{Sensor Cahaya}

Sensor cahaya adalah alat yang digunakan untuk merubah besaran cahaya menjadi besaran listrik. Prinsip kerja dari alat ini adalah mengubah energi dari foton menjadi elektron. Idealnya satu foton dapat membangkitkan satu elektron.

Salah satu sensor cahaya adalah LDR (Light Dependent Resistor). LDR atau fotoresistor adalah komponen elektronik yang dibuat dari semikonduktor yang memiliki resistansi tinggi, dan resistansinya akan menurun jika ada penambahan intensitas cahaya yang mengenainya. Contoh LDR adalah ORP12 yang cukup populer. Dalam keadaan gelap 
resistansinya sebesar $10 \mathrm{M} \Omega$ dan dalam keadaan terang sebesar $1 \mathrm{~K} \Omega$ atau kurang. (Widodo Budiharto, 2005: 31)

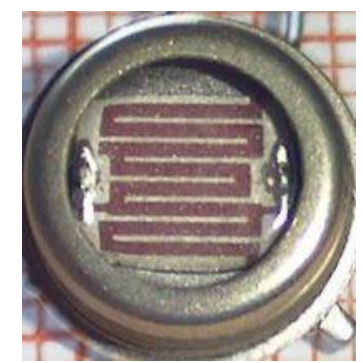

Gambar 3. LDR (Light Dependent Resistor)

Karakteristik dan kelebihan LDR:

1. Konduktansi sebagai fungsi intensitas cahaya masuk.

2. Resistansi berkisar dari $10 \mathrm{MW}$ (gelap) hingga $10 \mathrm{~W}$ (terang).

3. Waktu respon lambat hingga $10 \mathrm{~ms}$.

4. Untuk ukuran besar lebih murah dari sel fotovoltaik.

5. Dapat bekerja pada suhu $-30^{\circ} \mathrm{C}$ sampai $+70^{\circ-} \mathrm{C}$.

\section{Relay}

Karena dalam transistor tidak dapat berfungsi sebagai switch (saklar) tegangan AC atau tegangan tinggi yang arusnya lebih besar ( $>5$ amper). Sehingga dibutuhkan relay yang berfungsi sebagai saklar yang bekerja berdasarkan input-an yang dimilikinya.

Relay merupakan aplikasi elektromagnetik sesungguhnya dimana ia tersusun atas kumparan kawat beserta sebuah inti besi lunak. Pada dasarnya relay adalah sakelar elektromagnetik yang bekerja apabila arus mengalir melalui kumparannya, sehingga inti besi menjadi magnet dan manarik kontak bila gaya magnet mengalahkan gaya pagas yang melawannya.

Keuntungan relay:

- Dapat switch AC dan DC.

- Relay dapat switch tegangan tinggi.

- Relay pilihan yang tepat untuk switch arus yang besar.

- Realy dapat switch banyak kontak dalam 1 waktu. (Widodo Budiharto, 2005: 47).

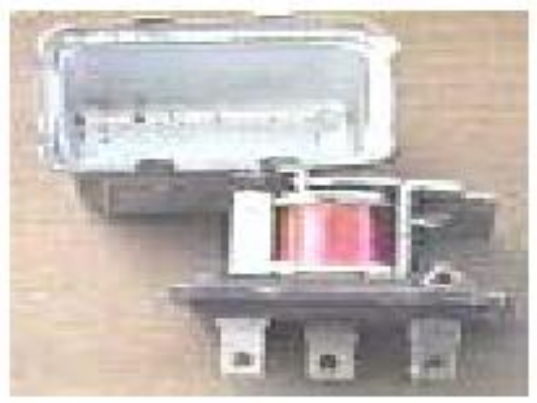

Gambar 4. Kontruksi relay

\section{Liquid Crystal Display (LCD)}

Liquid Cristal Display adalah modul tampilan yang mempunyai konsumsi daya yang relatif rendah dan terdapat sebuah controler CMOS didalamnya. Controler tersebut sebagai pembangkit ROM/RAM dan display data RAM. Semua fungsi tampilan di kontrol oleh suatu instruksi modul LCD dapat dengan mudah di-interface-kan dengan MPU. Ciriciri dari LCD M1632: 
1) Terdiri dari 32 karakter yang dibagi menjadi 2 baris dengan display dot matrix $5 \mathrm{X}$ 7 ditambah cursor

2) Karakter generator ROM dengan 192 karakter

3) Karakter generator RAM dengan 8 tipe karakter

4) $80 \times 8$ bit display data RAM

5) Dapat di-interface-kan dengan MPU 8 atau 4 bit

6) Dilengkapi fungsi tambahan: Display clear, cursor home, display ON/OFF, cursor $O N / O F F$, display character blink, cursor shift dan display shift

7) Internal data

8) Internal otomatis dan reset pada power $\mathrm{ON}$

9) +5 V power supply tunggal

Berikut ini merupakan pin-pin LCD berserta konfigurasinya:

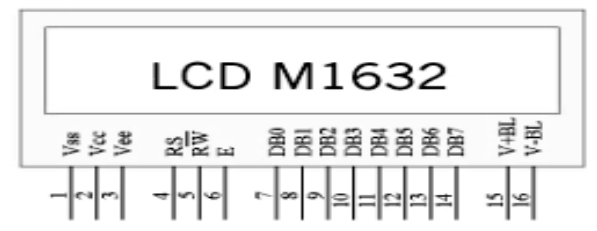

Gambar 5. LCD M1632

\section{Keypad}

Keypad sering digunakan sebagai media masukan dalam berbagai aplikasi elektronik. Rangkaian keypad berupa kaki baris dan kolom yang dapat dihubungkan dengan piranti luar. Bila salah satu tombol keypad ditekan maka keluaran yang dihasilkan berupa kombinasi baris dan kolom tersebut. Jenis keypad dibedakan berdasarkan jumlah baris dan kolomnya. Gambar 2.7 menunjukkan salah satu jenis keypad, yaitu keypad 4x4.

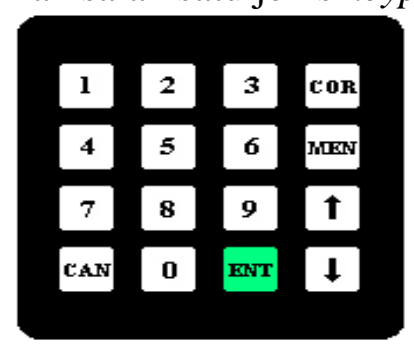

Gambar 6. Keypad 4x4

\section{Kerangka Konseptual}

Pada pengendali penerangan rumah jarak jauh yang telah penulis rancang, digunakan untuk menyalakan dan mematikan lampu rumah secara otomatis dengan memanfaatkan teknologi SMS dengan handphone sebagai pengontrolnya. Alasan penulis menggunakan SMS sebagai pengontrol karena kemampuan SMS dalam pengirimannya yang memiliki sifat waktu nyata (realtime) serta membutuhkan biaya operasional yang murah dan juga mampu menjangkau tempat dan jarak yang sangat luas, hal ini berlaku selama tersedianya jaringan yang menghubungkan jalur komunikasi terhadap handphone tersebut. Sehingga penggunaan media SMS sebagai pengontrol dianggap lebih efektif dalam hal pengontrolan jarak jauh dibandingkan dengan pengontrol lainnya.

Sistem kerja alat tersebut bisa menyalakan dan mematikan lampu secara otomatis tergantung dari perintah yang ada dalam SMS yang masuk. Selain itu alat akan mengirimkan SMS ketika lampu dinyalakan atau dimatikan tanpa perintah. SMS yang masuk akan diterjemahkan oleh mikrokontroler system dan selanjutnya akan mengaktifkan 
atau menonaktifkan control objek. Jadi kesimpulannya alat ini bisa dikendalikan oleh pemilik rumah dari mana saja. Sehingga meskipun rumah dalam keadaan tidak berpenghuni, namun lampunya dapat tetap menyala agar tidak menjadi sasaran pencurian.

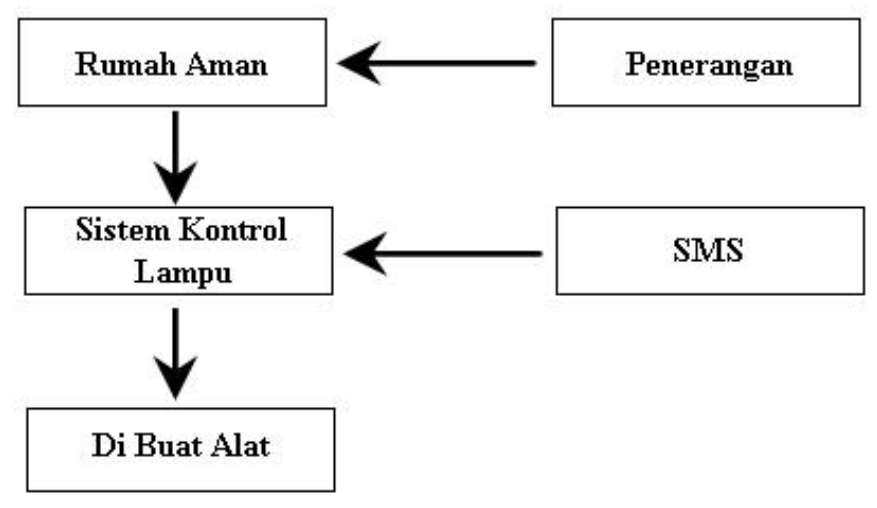

Gambar 7. Bagan Kerangka Konseptual

\section{METODE PENELITIAN \\ Jenis Penelitian}

Jenis penelitian adalah rancang bangun suatu sistem kontrol menggunakan SMS yang diaplikasikan pada pengendali penerangan rumah.

\section{Perencanaan dan Pembuatan Alat}

Perancangan dan pembuatan alat dibagi menjadi dua tahap yaitu tahap pembuatan perangkat keras (hardware) dan tahap pembuatan perangkat lunak (software)

\section{Pengujian Sistem Keseluruhan}

Tujaun pengujian sistem keseluruhan adalah mengetahui apakah secara keseluruhan alat dapat bekerja dengan baik sesuai dengan perencanaan.

Prosedur pengujian

- Memprogram mikrokontroler sesuai dengan sistem yang telah dirancang

- Menghubungkan LCD ke mikrokontroler dengan jalur pada port P0.0-P0.7, pin RS pada port P2.7 dan pin Enable pada port P2.6

- Menghubungkan masukan IC 74LS165 dari driver sensor dan saklar ke mikrokontroler pada port T1, WR dan RD

- Menghubungkan IC 74LS164 sebagai driver relay pada port INT0, INT1 dan T1.

- Menghubungkan keypad pada port P1.0-P1.7

- Menghubungkan handphone pada port RXD dan TXD

- Menghubungkan relay dengan lampu

- Mengaktifkan catu daya

\section{PEMBAHASAN}

Pengujian sistem alat dilakukan dengan memasang HP M35i dan rangkaian secara keseluruhan. Pengujian dilakukan dengan memberikan perintah yang dikirim dengan SMS melalui nomor XL 087859595353. Untuk memberikan perintah ke sistem, tidak semua SMS mampu dikenali oleh sistem. Hanya SMS tertentu yang sudah disesuaikan yang mampu dikenali oleh sistem. Mikrokontroler membaca isi SMS dan mengenali isi SMS yang menggunakan karakter huruf besar atau yang sesuai dengan kata kunci yang sesuai pada program. Ini karena pada program terdapat perintah AT+CMGR yaitu perintah 
membaca isi SMS. Ketika ada SMS masuk misalkan perintah L01_ON, maka dalam PDU

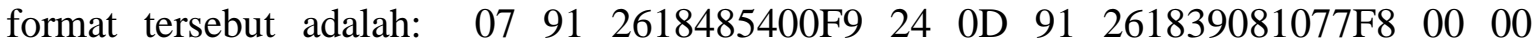
90402112046282 06 4C580CF47402. Dari format tersebut dapat diketahui beberapa informasi seperti:

Table 3. Pengujian Isi SMS

\begin{tabular}{|l|l|}
\hline \multicolumn{1}{|c|}{ Isi SMS } & \multicolumn{1}{c|}{ Keterangan } \\
\hline 07 & Panjang nomor SMSC \\
\hline 91 & Tipe SMSC dalam format internasional \\
\hline $2618485400 \mathrm{~F} 9$ & Nomor SMSC +62818445009 \\
\hline 24 & First octet dari SMS \\
\hline $0 \mathrm{D}$ & Panjang nomor pengirim \\
\hline 91 & Tipe nomor pengirim dalam format internasional \\
\hline $261839081077 \mathrm{~F} 8$ & Nomor pengirim +6281938001778 \\
\hline 00 & Identifikasi protocol yang digunakan \\
\hline 00 & Skema data pengkodean yang digunakan \\
\hline 90402112046282 & $\begin{array}{l}\text { Informasi waktu (berarti tanggal 12-04-2009 dan jam } \\
21: 40: 26)\end{array}$ \\
\hline 06 & Panjang data yang dibawa \\
\hline 4C580CF47402 & Data umum SMS dalam bentuk octet (berarti L01_ON) \\
\hline
\end{tabular}

Jika data umum yang dibaca program tidak sesuai maka mikrokontroler akan menghapus SMS karena dianggap SMS ilegal dengan perintah AT+CMGD. Dan jika perintah sesuai dengan data umum maka program akan mengeksekusi dan akan memberikan balasan menggunakan perntah AT+CMGS. Adapun perintah-perintah data umum SMS seperti pada tabel di bawah ini:

Table 4. Data Umum yang Telah Terprogram

\begin{tabular}{|c|c|}
\hline Data Umum & Keterangan \\
\hline 4C580CF47402 & L01_ON \\
\hline 4C580CF43402 & L01_OF \\
\hline 4C980CF47402 & L02_ON \\
\hline 4C980CF43402 & L02_OF \\
\hline 4CD80CF47402 & L03_ON \\
\hline 4CD80CF43402 & L03_OF \\
\hline 4C180DF47402 & L04_ON \\
\hline 4C180DF43402 & L04_OF \\
\hline 4C580DF47402 & L05_ON \\
\hline 4C580DF43402 & L05_OF \\
\hline 4C980DF47402 & L06_ON \\
\hline 4C980DF47402 & L06_ON \\
\hline 4CD80DF43402 & L07_OF \\
\hline 4CD80DF47402 & L07_ON \\
\hline 4CD80EF47402 & L08_ON \\
\hline 4C180EF43402 & L08_OF \\
\hline D3EC14F47402 & SYS_ON \\
\hline D3EC14F43402 & SYS_OF \\
\hline 412613F47402 & ALL_ON \\
\hline 412613F43402 & ALL_OF \\
\hline 536A905A9D02 & STATUS \\
\hline
\end{tabular}


Table 5. Perintah-perintah SMS dalam Sistem

\begin{tabular}{|c|c|c|}
\hline $\begin{array}{c}\text { Kata Kunci } \\
\text { Pengirim }\end{array}$ & SMS Balasan & Keterangan \\
\hline L01_ON & Lampu 1 hidup & \multirow{2}{*}{$\begin{array}{l}\text { ada } 8 \text { buah lampu yang } \\
\text { dapat dikendalikan }\end{array}$} \\
\hline L01_OF & Lampu 1 mati & \\
\hline SYS_ON & $\begin{array}{l}\text { Sistem Enabel } \\
\text { Stts: } 00000000\end{array}$ & \multirow{5}{*}{$\begin{array}{c}\text { setatus lampu tergantung } \\
\text { dari pembacaan sensor } \\
\text { cahaya yang dipasang di } \\
\text { dekat lampu (jika } 0 \text { berarti } \\
\text { lampu mati dan jika } 1 \text { berarti } \\
\text { lampu hidup) }\end{array}$} \\
\hline SYS_OF & $\begin{array}{l}\text { Sistem Disabel } \\
\text { Stts: } 00000000\end{array}$ & \\
\hline ALL_ON & Stts: 11111111 & \\
\hline ALL_OF & Stts: 00000000 & \\
\hline STATUS & Stts: 00000000 & \\
\hline
\end{tabular}

Untuk merubah setatus sistem selain dari SMS juga bisa juga secara manual dari keyped. Selain untuk merubah status sistem, keypad berfungsi untuk mengganti/merubah nomor handphone. Tetapi dari penelitian hanya bisa menggunakan nomor XL dan IM3. Selain nomor tersebut sistem tidak bisa menerimanya karena dari beberapa profider memiliki nomor pusat pesan yang berbeda-beda. Sedangkan XL dan IM3 meskipun memiliki nomor pusat pesan yang berbeda tetapi jumlah digitnya sama yakni 12 digit. Dan sistem ini telah di program dengan 12 digit pada pusat pesannya. Ini karena program akan membaca perintah atau data umum sesuai dengan jumlah karakter pada data.

Data umum pada format PDU ada pada karakter ke 56. Misalkan jika perintah L01_ON seperti berikut: 0791 2618485400F9 24 0D 91 261839081077F8 000090402112046282 $06 \underline{\text { 4C580CF47402 }}$ (penjelasan isi dalam format PDU ada pada tabel 4.5). Isi PDU yang diberi underline merupakan data umum yang akan dibaca program. Jika pusat pesan yang yang digunakan hanya 10 digit otomatis data umum pada karakter ke 54 karena ada selisish 2 digit. Sedangkan sistem telah diprogram untuk mmembaca karakter ke 56. Format PDU yang di baca adalah sebagai berikut 0791 26184854F0 24 0D 91 261839081077F8 0000 9040211204628206 4C580CF47402. Sehingga program tidak akan bisa mengeksekusi perintah karena isi pesan atau pesan umumnya tidak sesuai dan akan menganggap sebagai SMS ilegal yang otomatis akan terhapus.

Selain itu lampu juga bisa dikendalikan secara manual dari tombol saklar. Tetapi jika status sistem on maka secara otomatis setiap perubahan keadaan lampu ON/OFF akan mengirimkan keadaan lampu. Tetapi jika sistem off maka sistem tidak akan mengirimkan perubahan keadaan lampu.

Berdasarkan pengujian secara keseluruhan yang telah dilakukan, diketahui bahwa: LCD, keypad, shift register, relay dan driver relay, LDR (sensor cahaya) dan driver sensor dan mikrokontroler dapat berjalan sesuai dengan perancangan. Setiap bagian dalam sistem pada perancangan ini bekerja sesuai kontrol masing-masing.

Tetapi dalam penelitian ini masih terbatas pada kontrol lampu, dan hanya mengontrol 8 buah lampu. Sistem kontrol lampu yang dibuat masih dalam bentuk miniatur dan nantinya bisa di aplikasikan ke bentuk nyata pada lapu rumah ataupun pada peralatan rumah.

\section{KESIMPULAN}

Dari hasil penelitian dan pembahasan tentang Kendali Penerangan Rumah Jarak Jauh Menggunakan Short Message Service (SMS) yang telah diuraikan maka dapat ditarik kesimpulan sebagai berikut: 
1. Sistem yang dibuat ini dapat bekerja baik, dalam menerima SMS, mengolah data SMS, kemudian mengirimkan perintah ke sistem sesuai dengan format dan membalas kembali SMS tersebut sesuai dengan respon sensor cahaya. Alat ini dapat melakukan pengontrolan jarak jauh hingga beratus-ratus bahkan beribu-ribu kilometer tergantung luasnya jaringan GSM. Cepat atau lambat sampainya SMS sangat tergantung pada keadaan jaringan dari masing-masing service centre.

2. Secara keseluruhan alat komunikasi antara handphone dengan mikrokontroler secara serial ini dapat bekerja dan berfungsi sebagaimana yang diharapkan sehingga dapat dimanfaatkan sebagai alat pengontrol jarak jauh. Alat pengontrol ini dapat melakukan pengontrolan ketika terdapat SMS di memori handphone. Handphone yang bisa digunakan hanya yang suport dengan AT-Command. Serta kabel data handphone yang digunakan harus bisa berkomunikasi secara fullduplex untuk mengirim sekaligus menerima data dari dan ke mikrokontroler.

\section{DAFTAR PUSTAKA}

Annonymous. 2002. Atmel AT89S8252. http://www.atmel.com

Budiharto, Widodo dan Sigit Firmansah. 2005. Elektronika Digital dan Mikroprosesor. Yogyakarta: ANDI.

Budiharto, Widodo. 2004. Interfacing Computer Dan Mikrokontroler. Jakarta: PT Elex Media Koputindo

ETSI, 1996, Technical Realization of the Short Message Service (SMS) Pont-to-Pont (PP) (GSM 03.40). http://www.mobilecity.cz/doc/GSM_03.40_5.3.0.pdf

Green, DC. 1995. Data Communication. Terjemah Ir. P. Insap Santoso, M.Sc. Yogyakarta: Andi.

Gupta, Puneet. 2008. Short Message Service: What, How and Where? http://www.wirelessdevnet.com/channels/sms/features/sms.html

Le Bodic, Gwenael, November 2002, "Mobile Messaging: SMS, EMS and MMS," IEEE Vehicular Technology Society News, http://www.wileyerupe.com

Malik, Moh. Ibnu. 2003. Mikrokontroler Atmel AT89S8252. Yogyakarta: Gava Media.

Malvino, Albert Paul. 2003. Prinsip-prinsip Elektronika. Jakarta: Salemba Teknika.

Silalahi, Nuraini. 2002. Layanan Informasi dan Telekomunikasi Mobil Nirkabel. Jakarta: PT Elex Media Komputindo.

Snyder, Randall A. Dan Michael D. Gallagher. 2001. Wireless telecommunications Networking with ANSI-41. New York: McGraw-Hill.

WAVECOM, 2000, An introduction to the SMS in PDU mode GSM Recommendation phase2+.www.ascend-tech.com.cn/sustain/SMS_PDU-mode.pdf

Zakaria, Teddy Marcus dan Josef Widiadhi. 2006. Aplikasi SMS untuk Berbagai Keperluan. Bandung: Informatika. 